Revista Brasileira de

Engenharia Agrícola e Ambiental

v.16, n.1, p.108-112, 2012

Campina Grande, PB, UAEA/UFCG - http://www.agriambi.com.br

agriambi Protocolo 145.10 - 19/08/2010 • Aprovado em 20/11/2011

\title{
Conservação de sementes de ipê-roxo
}

\author{
Leila Martins ${ }^{2}$, Antonio A. do Lago $^{3} \&$ Silvio M. Cícero ${ }^{4}$
}

RESU M O

O objetivo desta pesquisa foi estudar o comportamento fisiológico de sementes de ipê-roxo (Tabebuia heptaphylla (Vell.) Toledo) durante 0 amazenamento. Frutos colhidos manualmente de 15 plantasmatrizes foram colocados em ambiente sombreado para secagem complementar e posterior extração manual das sementes; primeiro, determinou-se o grau de umidade inicial das sementes $(15,6 \%)$ e, em seguida, as sementes remanescentes foram submetidas a secagem para obtenção dos demais graus de umidade desejados $(11,5,8,0$ e 4,3\%). As amostras correspondentes aos diferentes graus de umidade foram armazenadas em câmaras, na temperaturas de 10, 20 e $-196{ }^{\circ} \mathrm{C}$. N o início e após 120,240 e 360 dias de armazenamento, as sementes foram submetidas a diversas avaliações fisiológicas. 0 delineamento experimental foi o inteiramente casualizado, em esquema fatorial, com 4 tratamentos (grau de umidade) no início do armazenamento e 12 tratamentos (4 grau de umidade x 3 condições térmicas), em cada época de avaliação, durante o armazenamento. A comparação das médias foi realizada pelo Teste de Tukey a 5\%. A conservação das sementes de ipê-roxo com teores de água de 15,6,11,5, 8,1 e 4,3\% é favorecida no armazenamento a 10 e $-196^{\circ} \mathrm{C}$.

Palavras-chave: Bignoniaceae, Tabebuia heptaphylla, pau-d'arco-roxo, propagação

\section{Preservation of Tabebuia heptaphylla (Vell.) Toledo seeds}

\begin{abstract}
The objective of this research was to study the physiological performance of Tabebuia heptaphylla (Vell.) Toledo seeds during storage. Fruits from 15 mother plants were hand picked and placed under shade to finish drying and to ease further manual extraction of seeds. Firstly, the initial moisture content of the seeds was determined, which was $15.6 \%$. Following that, the remaining seeds were submitted to drying at ambient temperature inside a glass desicator in order to obtain the other desired moisture contents $(11.5,8.1$ and $4.3 \%)$. The samples, corresponding to the different moisture contents were stored inside chambers at temperatures of 10,20 and $-196^{\circ} \mathrm{C}$. At the beginning and after 120, 240 and 360 days of storage, the seeds were submitted to several physiological evaluations. The experiment was a factorial, in a completely randomized design, with 4 treatments (moisture contents) at beginning of storage and 12 treatments (4 moisture contents $\times 3$ thermal conditions), in each evaluation date, during storage. Mean comparison was made by the Tukey test at $5 \%$. It was concluded that the preservation of Tabebuia heptaphylla seeds, at water contents $15.6,11.5,8.1$ and $4,3 \%$ is favored by temperatures from 10 and $-196{ }^{\circ} \mathrm{C}$.
\end{abstract}

Key words: Bignoniaceae, Tabebuia heptaphylla, storage, propagation

\footnotetext{
${ }^{1}$ Trabalho realizado com auxílio financeiro da FAPESP

2 D epartamento de Sementes Mudas e M atrizes /CATI. C P 962, CEP 13070-178, Campinas, SP. Fone: (19) 3743-3835. E-mail: leila@cati.sp.gov.br

3 Instituto Agronômico de Campinas/APTA. CP 28, CEP 13001-970, Campinas, SP. Fone: (19) 3202-1741. Email: aalago@iac.sp.gov.br

${ }^{4}$ ESALQ/U SP, bolsista de produtividade em pesquisa do CN Pq, CP 09, CEP 13418-900, Piracicaba, SP. E-mail: smcicero@esalq.usp.br
} 


\section{INTRODUÇÃO}

O ipê-roxo (Tabebuia heptaphylla (Vell.) Toledo), popularmente conhecido como ipê-roxo, ipê-roxo-de-setefolhas e ipê-preto, entre outros, é uma Bignoniaceae de porte arbóreo, alcançando alturas de dez a vinte metros; seu florescimento é abundante apresentando, com a queda das folhas, maciças e vistosas florações, proporcionando efeito paisagístico de rara beleza (Lorenzi, 2002). Por essas razões tem sido indicada nos trabalhos de restauração de ecossistemas florestais e de paisagismo; em reflorestamentos é utilizada na reposição de mata ciliar para locais sem inundação.

Espécies do gênero Tabebuia possuem período de viabilidade natural relativamente curto, o que representa dificuldades no estabelecimento de técnicas de cultivo visando à produção de mudas (Cabral et al., 2003). Entretanto, Degan et al. (2001) e Marques et al. (2004) afirmam que as sementes de ipê não apresentam vida curta, desde que armazenadas de forma adequada.

Segundo Roberts (1973), sementes ortodoxas podem ser armazenadas com grau de umidade inferior a $5 \%$ e a baixas temperaturas, por longo período, sem prejudicar seu potencial germinativo, mas Degan et al. (2001) afirmaram que sementes de Tabebuia roseo-alba (Ridl.) (ipê-branco) liofilizadas e apresentando 3,7\% de água, tiveram significativa redução de germinabilidade depois de 60 dias de armazenamento em ambiente de laboratório e depois de 120 dias em câmara seca. Da mesma forma, Borba Filho \& Perez (2009) verificaram perda total de viabilidade em sementes de ipê-branco (Tabebuia roseo alba) e ipê-roxo (Tabebuia impetiginosa) após 120 dias armazenadas em condição de laboratório $\left(21\right.$ a $31^{\circ} \mathrm{C} ; 40$ a $78 \%$ de umidade relativa do ar). Já Martins et al. (2009a), observaram que a conservação de sementes de ipê-branco (Tabebuia roseo alba), com teores de água de 10,1 e 8,3\% é favorecida pelo armazenamento por 360 dias, nas temperaturas de $10 \mathrm{e}-20^{\circ} \mathrm{C}$.

Oliveira et al. (2008) verificaram, em sementes de ipê-amarelo (Tabebuia crysotricha) conservadas em câmara seca, germinação de aproximadamente 50\% após 90 dias de armazenamento. Todavia, sementes de cedro (Cedrella fissilis) com teor de água de $8,1 \%$ armazenadas em embalagem impermeável a $20^{\circ} \mathrm{C}$ apresentaram germinação de $91,7 \%$ após 360 dias (Martins \& Lago, 2008).

Segundo Marques et al. (2004) pelo interesse nos ipês tornase indispensável o conhecimento de métodos adequados de conservação das sementes para prolongar ao máximo o período de armazenamento e disponibilizar, no mercado, sementes com alto poder germinativo.

Desta maneira e se considerando a importância da espécie e, sobretudo, da produção de mudas para reposição de matas, o objetivo desta pesquisa foi o estudo do comportamento fisiológico das sementes de ipê-roxo (Tabebuia heptaphylla (Vell.) Toledo) armazenadas durante 360 dias.

\section{MAterial e MÉTOdos}

Os frutos foram coletados maduros, porém ainda fechados, de 15 plantas matrizes e colocados em ambiente sombreado para secagem complementar e posterior extração das sementes. Primeiro, foi determinado o grau de umidade inicial das sementes (Brasil, 1992) e, paralelamente, removida uma amostra representante do tratamento controle, com o maior teor de água a ser estudado $(15,6)$; em seguida, as sementes remanescentes foram submetidas a secagem em embalagem de vidro com tampa (condição hermética) contendo sílica-gel com indicador azul ( $\varnothing=4-8 \mathrm{~mm}$ ), renovada regularmente, para obtenção dos demais graus de umidade desejados $(11,5,8,1$ e $4,3 \%)$.

Os teores de água foram obtidos com acompanhamento da perda de massa das sementes durante a secagem. Para tanto, as amostras de sementes para o monitoramento, com massas iniciais previamente conhecidas, foram acondicionadas em sacos de filó e distribuídas nas embalagens de vidro, para pesagens a intervalos regulares. As massas finais das amostras, correspondentes a cada um dos graus de umidade desejados, foram calculadas por meio da equação descrita por Cromarty et al. (1985):

$$
\mathrm{Mf}=\mathrm{Mi}(100-\mathrm{Ui})(100-\mathrm{Uf})-1
$$

donde:
Mf - massa da amostra (g) após a secagem
Mi - massa da amostra (g) antes da secagem
Ui - grau de umidade (\%) antes da secagem
Uf - grau de umidade (\%) desejado após a secagem

À medida em que o grau de umidade estava próximo do desejado, amostras foram retiradas, homogeneizadas e divididas em frações que, por sua vez, foram embaladas individualmente em sacos de polietileno impermeável de $0,1 \mathrm{~mm}$ de espessura (Martins et al., 2009a, b, c; Nascimento et al., 2010) e mantidas a $10 \pm 2{ }^{\circ} \mathrm{C}$, provisoriamente, até a obtenção do grau de umidade desejado.

As amostras, correspondentes aos diferentes graus de umidade, foram armazenadas em câmaras a 10 e $20^{\circ} \mathrm{C}$ e nitrogênio líquido a $-196^{\circ} \mathrm{C}$.

No início, as sementes foram submetidas às avaliações discriminadas a seguir.

Grau de umidade: foi feito a $105 \pm 3{ }^{\circ} \mathrm{C}$ por $24 \mathrm{~h}$, pelo método da estufa (Brasil, 1992), em duas amostras de $1 \mathrm{~g}$ por repetição. Os resultados obtidos com base na massa úmida (b.u.) foram expressos em porcentagem.

Germinação: foi determinada utilizando-se 6 repetições de 20 sementes dentro de caixas transparentes $(11 \times 11 \times 3,3 \mathrm{~cm})$ mantidas a $25^{\circ} \mathrm{C}$ e fotoperíodo de $8 \mathrm{~h}$. O substrato foi umedecido com volume de água equivalente a três vezes a sua massa sem hidratação. As avaliações, feitas aos 11, 16 e 28 dias após a instalação do teste, forneceram dados que foram expressos em porcentagem de plântulas normais (Brasil, 1992).

Emergência de plântulas: foi avaliada semeando-se 6 repetições de 20 sementes, semeadas entre areia $(0,5 \mathrm{~cm}$ de profundidade), autoclavada a $120{ }^{\circ} \mathrm{C}$ por $2 \mathrm{~h}$ e disposta em caixas transparentes ( $11 \times 11 \times 3,3 \mathrm{~cm})$, de plástico e sem tampa. As caixas foram distribuídas sobre bancada de alvenaria, em interior de laboratório e sob luz indireta com temperatura e umidade relativa variável e sem monitoramento. A disponibilidade hídrica foi mantida a aproximadamente $60 \%$ da 
capacidade de retenção de água. Foram consideradas emersas as plântulas que, após 30 dias da instalação do teste, apresentaram a parte área exposta acima da superfície do substrato.

Velocidade de emergência de plântulas: foi obtida contandose o número diário de indivíduos emersos no teste de emergência de plântulas e se calculando o índice de velocidade de emergência (IVE) de acordo com os procedimentos descritos por Marcos Filho et al. (1987).

Comprimento do hipocótilo de plântulas: foi verificado aos 30 dias após a instalação do teste de emergência, quando foram tomadas as distâncias (cm) entre a região de transição da raiz com o hipocótilo e a região de inserção das folhas cotiledonares. Os dados médios foram obtidos pelo quociente entre o somatório das medidas registradas em cada determinação e o número de sementes utilizadas (Vanzolini et al., 2007).

Após 120, 240 e 360 dias de armazenamento as sementes foram submetidas aos testes de germinação, emergência de plântulas, velocidade de emergência de plântulas e comprimento do hipocótilo de plântulas, conforme descrito anteriormente.

O delineamento experimental foi o inteiramente casualizado, em esquema fatorial, com 4 tratamentos (graus de umidade) no início do armazenamento e 12 tratamentos (4 teores de umidade x 3 condições térmicas) e 6 repetições, em cada época de avaliação, durante o armazenamento. A comparação das médias foi realizada pelo Teste de Tukey $(p>0,05)$. Os dados de germinação e emergência de plântulas foram transformados em:

$$
\operatorname{arcoseno} \sqrt{\mathrm{x} / 100}
$$

em que x se refere à porcentagem de germinação ou de emergência de plântulas mas nas tabelas são apresentadas as médias sem transformação(\%).

\section{RESULTADOS E DISCUSSÃO}

As avaliações fisiológicas, de germinação, emergência, índice de velocidade de emergência e comprimento da parte aérea de plântulas realizadas no início do armazenamento (Tabela 1) mostraram que os teores de água estudados não prejudicaram a qualidade fisiológica das sementes, uma vez

Tabela 1. Teor de umidade $\left(\% \mathrm{H}_{2} \mathrm{O}\right)$, germinação $(\mathrm{G})$, emergência de plântulas (E), comprimento da parte aérea (CPA) e índice de velocidade de emergência (IVE) obtidos após semeadura de sementes de ipê-roxo (T. heptaphylla) no início do armazenamento

\begin{tabular}{ccccc}
\hline $\begin{array}{c}\text { Tratamentos } \\
\left(\% \mathbf{H}_{\mathbf{2}} \mathbf{0}\right)\end{array}$ & $\mathbf{G}(\%)$ & $\mathbf{E}(\%)$ & CPA $(\mathbf{c m})$ & IVE \\
15,6 & $40 \mathrm{a}$ & $42 \mathrm{a}$ & $4,30 \mathrm{a}$ & $0,88 \mathrm{a}$ \\
11,5 & $43 \mathrm{a}$ & $35 \mathrm{a}$ & $3,36 \mathrm{a}$ & $0,65 \mathrm{a}$ \\
8,1 & $35 \mathrm{a}$ & $46 \mathrm{a}$ & $4,55 \mathrm{a}$ & $0,88 \mathrm{a}$ \\
4,3 & $44 \mathrm{a}$ & $45 \mathrm{a}$ & $4,60 \mathrm{a}$ & $0,82 \mathrm{a}$ \\
\hline $\mathrm{CV}(\%)$ & 14,72 & 18,61 & 22,49 & 21,95 \\
\hline
\end{tabular}

Médias seguidas da mesma letra na coluna não diferem entre si pelo teste de Tukey $(p>0,05)$. $\mathrm{CV}$ - coeficiente de variação que essas apresentaram germinação semelhante em todos os tratamentos.

No conjunto de dados obtidos na avaliação da germinação (Tabela 2), que apresentou valor médio de $40 \%$ devido, provavelmente, a fatores climáticos adversos ocorridos na fase da fertilização das sementes, observa-se que as temperaturas de 10 e $-196{ }^{\circ} \mathrm{C}$ favoreceram o desempenho das sementes durante todo o período. Este fato confirma as observações de Degan et al. (2001) de que as sementes de ipê não apresentam vida curta, desde que armazenadas de forma adequada.

Tabela 2. Germinação (G) de sementes de ipê-roxo (T. heptaphylla): valores médios (\%) obtidos durante 0 armazenamento com diferentes teores de umidade (U\%), sob diferentes temperaturas $\left(\mathrm{T}^{\circ} \mathrm{C}\right)$

\begin{tabular}{ccccc}
\hline \multirow{2}{*}{ Fator de variação } & \multirow{2}{*}{ Tratamento } & \multicolumn{3}{c}{ Período de armazenamento (dias) } \\
\cline { 2 - 5 } & & $\mathbf{1 2 0}$ & $\mathbf{2 4 0}$ & $\mathbf{3 6 0}$ \\
$\mathrm{U}(\%)$ & 15,6 & $33 \mathrm{~b}$ & $28 \mathrm{bc}$ & $22 \mathrm{a}$ \\
& 11,5 & $38 \mathrm{ab}$ & $40 \mathrm{a}$ & $27 \mathrm{a}$ \\
& 8,1 & $43 \mathrm{a}$ & $37 \mathrm{ab}$ & $30 \mathrm{a}$ \\
$\mathrm{T}\left({ }^{\circ} \mathrm{C}\right)$ & 4,3 & $39 \mathrm{ab}$ & $27 \mathrm{c}$ & $21 \mathrm{a}$ \\
\hline \multirow{6}{*}{} & 10 & $44 \mathrm{a}$ & $41 \mathrm{a}$ & $39 \mathrm{a}$ \\
& 20 & $34 \mathrm{~b}$ & $26 \mathrm{~b}$ & $6 \mathrm{c}$ \\
& -196 & $37 \mathrm{ab}$ & $32 \mathrm{~b}$ & $31 \mathrm{~b}$ \\
\hline \multirow{3}{*}{$\mathrm{U} \times \mathrm{T}$} & $15,6 / 10$ & $44 \mathrm{a}$ & $39 \mathrm{a}$ & $31 \mathrm{a}$ \\
& $11,5 / 10$ & $40 \mathrm{a}$ & $43 \mathrm{a}$ & $42 \mathrm{a}$ \\
& $8,1 / 10$ & $49 \mathrm{a}$ & $49 \mathrm{a}$ & $45 \mathrm{a}$ \\
& $4,3 / 10$ & $44 \mathrm{a}$ & $34 \mathrm{a}$ & $37 \mathrm{a}$ \\
\cline { 2 - 5 } & $15,6 / 20$ & $25 \mathrm{~b}$ & $12 \mathrm{c}$ & $5 \mathrm{a}$ \\
& $11,5 / 20$ & $37 \mathrm{a}$ & $40 \mathrm{a}$ & $7 \mathrm{a}$ \\
& $8,1 / 20$ & $39 \mathrm{a}$ & $29 \mathrm{ab}$ & $11 \mathrm{a}$ \\
& $4,3 / 20$ & $34 \mathrm{a}$ & $21 \mathrm{bc}$ & $0 \mathrm{a}$ \\
\cline { 2 - 5 } & $15,5 /-196$ & $30 \mathrm{a}$ & $32 \mathrm{a}$ & $31 \mathrm{a}$ \\
& $11,5 /-196$ & $37 \mathrm{a}$ & $36 \mathrm{a}$ & $32 \mathrm{a}$ \\
& $8,0 /-196$ & $42 \mathrm{a}$ & $33 \mathrm{a}$ & $32 \mathrm{a}$ \\
& $4,3 /-196$ & $39 \mathrm{a}$ & $27 \mathrm{a}$ & $27 \mathrm{a}$ \\
\hline
\end{tabular}

Médias seguidas da mesma letra na coluna dentro dos fatores de variação e interação dos fatores, não diferem entre si pelo teste de Tukey $(p>0,05)$. CV - coeficiente de variação

De maneira similar, Martins et al. (2009c) obtiveram resultados favoráveis na conservação de sementes de ipê-amarelo (Tabebuia chrysotricha) armazenadas com teor de água em torno de $11,9 \%$ nas temperaturas de $10 \mathrm{e}-12^{\circ} \mathrm{C}$. Berbert et al. (2008) afirmaram que o potencial fisiológico de sementes de mamão (Carica papaia L.) com 7,7\% de água, é favorecido quando armazenadas por 120 dias a $15^{\circ} \mathrm{C}$. Adicionalmente, Borba Filho \& Perez (2009) concluíram que o acondiciomamento em lata e manutenção em geladeira é uma condição adequada para armazenar sementes de Tabebuia roseo alba $(7,9 \%$ de água) e Tabebuia impetiginosa (8,3\% de água). De acordo com Kartha (1985), em sementes armazenadas a temperaturas ultrabaixas $\left(-180,-196^{\circ} \mathrm{C}\right)$ o metabolismo celular e os processos bioquímicos são substancialmente reduzidos; consequentemente, a deterioração biológica do material durante o armazenamento, é mínima.

Entretanto, as sementes com teores de água de 15,6, 11,5, 8,1 e $4,3 \%$ armazenadas a $20{ }^{\circ} \mathrm{C}$ tiveram o desempenho fisiológico prejudicado aos 360 dias de armazenamento, sendo que na combinação $15,6 \%$ de água e temperatura de $20^{\circ} \mathrm{C}$, o 
desempenho foi inferior aos 120 dias quando comparado com o das demais. Este fato pode ser explicado porque, segundo Harrington (1972), em sementes armazenadas com teores de água superiores a $12 \%$ a deterioração é mais rápida em embalagens impermeáveis à água do que nas permeáveis devido à aceleração das atividades respiratórias da semente e dos fungos que a acompanham.

De modo similar aos resultados obtidos no teste de germinação, os testes de vigor, ou seja, emergência de plântulas (Tabela 3), índice de velocidade de emergência (Tabela 4) e comprimento da parte aérea (Tabela 5), permitiram verificar que a temperatura de armazenamento de $20^{\circ} \mathrm{C}$ conduziu a intenso processo de deterioração e, consequentemente, desfavoreceu a conservação das sementes; de forma especial, o armazenamento após 240 dias, com teor de água mais elevado $(15,56 \%)$ e a temperatura de $20^{\circ} \mathrm{C}$ prejudicaram particularmente a qualidade das sementes. Observam-se valores reduzidos de plantas emersas aos 240 dias, em razão das baixas temperaturas ocorridas no mês de junho quando a avaliação de emergência das plântulas foi realizada. Desta forma, observa-se que o teor de água de 15,5, 11,5, 8,0 e 4,3 e as temperaturas de 10 e $-196{ }^{\circ} \mathrm{C}$ favoreceram a conservação das sementes. Por exemplo, Martins et al. (2009b) afirmaram que as sementes de ipê-roxo (Tabebuia impetiginosa (Mart. Ex DC.) Standl.) podem ser previamente secadas a 4,2\% de água e posteriormente imersas em nitrogênio líquido por pelo menos 360 dias, sem redução da qualidade fisiológica. Adicionalmente, Kissmann et al. (2009) mencionam que sementes de farinha seca (Albizzia hasslerri) podem ser armazenadas por 90 dias em câmara seca, apresentando germinação superior a $50 \%$.

Tabela 3. Emergência (E) de plântulas de ipê-roxo (T. heptaphylla): valores médios (\%) obtidos durante 0 armazenamento com diferentes teores de umidade (U\%), sob diferentes temperaturas $\left(\mathrm{T}^{\circ} \mathrm{C}\right)$

\begin{tabular}{|c|c|c|c|c|}
\hline \multirow{2}{*}{ Fator de variação } & \multirow{2}{*}{ Tratamento } & \multicolumn{3}{|c|}{ Período de armazenamento (dias) } \\
\hline & & 120 & 240 & 360 \\
\hline U (\%) & $\begin{array}{c}15,6 \\
11,5 \\
8,1 \\
4,3\end{array}$ & $\begin{array}{l}35 b \\
45 a \\
40 a b \\
34 b\end{array}$ & $\begin{array}{l}11 b \\
19 a \\
17 a b \\
17 a b\end{array}$ & $\begin{array}{l}29 a \\
30 a \\
29 a \\
31 a\end{array}$ \\
\hline $\mathrm{T}\left({ }^{\circ} \mathrm{C}\right)$ & $\begin{array}{c}10 \\
20 \\
-196\end{array}$ & $\begin{array}{l}40 a \\
40 a \\
35 a\end{array}$ & $\begin{array}{r}17 b \\
26 a \\
5 c\end{array}$ & $\begin{array}{l}41 a \\
13 b \\
34 a\end{array}$ \\
\hline \multirow{3}{*}{$U \times T$} & $\begin{array}{c}15,6 / 10 \\
11,5 / 10 \\
8,1 / 10 \\
4,3 / 10 \\
\end{array}$ & $\begin{array}{l}30 b \\
55 a \\
39 b \\
35 b\end{array}$ & $\begin{array}{l}16 a \\
19 a \\
14 a \\
20 a \\
\end{array}$ & $\begin{array}{l}45 a \\
35 a \\
40 a \\
46 a\end{array}$ \\
\hline & $\begin{array}{c}15,6 / 20 \\
11,5 / 20 \\
8,1 / 20 \\
4,3 / 20\end{array}$ & $\begin{array}{l}37 a \\
42 a \\
42 a \\
40 a\end{array}$ & $\begin{array}{l}6 b \\
36 a \\
32 a \\
29 a\end{array}$ & $\begin{array}{r}9 a \\
16 a \\
16 a \\
12 a\end{array}$ \\
\hline & $\begin{array}{c}15,6 /-196 \\
11,5 /-196 \\
8,1 /-196 \\
4,3 /-196\end{array}$ & $\begin{array}{l}37 a \\
38 a \\
38 a \\
27 a \\
\end{array}$ & $\begin{array}{r}11 a \\
2 a \\
5 a \\
2 a \\
\end{array}$ & $\begin{array}{l}34 a \\
39 a \\
31 a \\
35 a\end{array}$ \\
\hline $\mathrm{CV}(\%)$ & & 18,51 & 41,41 & 31,57 \\
\hline
\end{tabular}

Médias seguidas da mesma letra na coluna, dentro dos fatores de variação e interação dos fatores, não diferem entre si pelo teste de Tukey $(p>0,05)$. CV - coeficiente de variação
Tabela 4. Índice de velocidade de emergência (IVE) de plântulas de ipê-roxo (T. heptaphylla): val ores médios (\%) obtidos durante 0 armazenamento com diferentes teores de umidade $(\mathrm{U} \%)$, sob diferentes temperaturas $\left(\mathrm{T}^{\circ} \mathrm{C}\right)$

\begin{tabular}{|c|c|c|c|c|}
\hline \multirow{2}{*}{$\begin{array}{l}\text { Fator de } \\
\text { variação }\end{array}$} & \multirow{2}{*}{ Tratamento } & \multicolumn{3}{|c|}{ Período de armazenamento (dias) } \\
\hline & & 120 & 240 & 360 \\
\hline U (\%) & $\begin{array}{c}15,6 \\
11,5 \\
8,1 \\
4,3\end{array}$ & $\begin{array}{l}0,74 \mathrm{~b} \\
1,01 \mathrm{a} \\
0,87 \mathrm{ab} \\
0,73 \mathrm{~b}\end{array}$ & $\begin{array}{l}0,09 \mathrm{~b} \\
0,16 \mathrm{a} \\
0,18 \mathrm{a} \\
0,16 \mathrm{ab}\end{array}$ & $\begin{array}{l}0,65 a \\
0,60 a \\
0,67 a \\
0,68 a\end{array}$ \\
\hline $\mathrm{T}\left({ }^{\circ} \mathrm{C}\right)$ & $\begin{array}{c}10 \\
20 \\
-196\end{array}$ & $\begin{array}{l}0,89 a \\
0,86 a b \\
0,75 b\end{array}$ & $\begin{array}{l}0,17 \mathrm{~b} \\
0,23 \mathrm{a} \\
0,04 \mathrm{c}\end{array}$ & $\begin{array}{l}0,96 a \\
0,24 c \\
0,76 b\end{array}$ \\
\hline \multirow{3}{*}{ U xT } & $\begin{array}{c}15,6 / 10 \\
11,5 / 10 \\
8,1 / 10 \\
4,3 / 10\end{array}$ & $\begin{array}{l}0,78 \mathrm{~b} \\
1,17 \mathrm{a} \\
0,83 \mathrm{~b} \\
0,77 \mathrm{~b}\end{array}$ & $\begin{array}{l}0,13 a \\
0,16 a \\
0,15 a \\
0,24 a\end{array}$ & $\begin{array}{l}1,16 \mathrm{a} \\
0,65 \mathrm{~b} \\
0,99 \mathrm{ab} \\
1,04 \mathrm{a}\end{array}$ \\
\hline & $\begin{array}{c}15,6 / 20 \\
11,5 / 20 \\
8,1 / 20 \\
4,3 / 20\end{array}$ & $\begin{array}{l}0,67 \mathrm{~b} \\
1,03 \mathrm{a} \\
0,93 \mathrm{ab} \\
0,83 \mathrm{ab}\end{array}$ & $\begin{array}{l}0,05 \mathrm{~b} \\
0,31 \mathrm{a} \\
0,33 \mathrm{a} \\
0,23 \mathrm{a}\end{array}$ & $\begin{array}{l}0,16 \mathrm{a} \\
0,28 \mathrm{a} \\
0,31 \mathrm{a} \\
0,21 \mathrm{a}\end{array}$ \\
\hline & $\begin{array}{c}15,6 /-196 \\
11,5 /-196 \\
8,1 /-196 \\
4,3 /-196 \\
\end{array}$ & $\begin{array}{l}0,77 \mathrm{a} \\
0,83 \mathrm{a} \\
0,84 \mathrm{a} \\
0,58 \mathrm{a}\end{array}$ & $\begin{array}{l}0,09 a \\
0,02 a \\
0,06 a \\
0,01 a\end{array}$ & $\begin{array}{l}0,65 a \\
0,88 a \\
0,72 a \\
0,79 a\end{array}$ \\
\hline \multicolumn{2}{|c|}{$\mathrm{CV}(\%)$} & 17,03 & 45,15 & 30,13 \\
\hline
\end{tabular}

Médias seguidas de mesma letra na coluna, dentro dos fatores de variação e interação dos fatores, não diferem entre si pelo teste de Tukey $(p>0,05)$. CV - coeficiente de variação

Tabela 5. Comprimento da parte aérea (CPA) de plântulas de ipê-roxo (T. heptaphylla): valores médios (\%) obtidos durante 0 armazenamento com diferentes teores de umidade $(U \%)$, sob diferentes temperaturas $\left(\mathrm{T}^{\circ} \mathrm{C}\right)$

\begin{tabular}{ccccc}
\hline Fator de & \multirow{2}{*}{ variação } & Tratamento & \multicolumn{3}{c}{ Período de armazenamento (dias) } \\
\cline { 3 - 5 } & & $\mathbf{1 2 0}$ & $\mathbf{2 4 0}$ & $\mathbf{3 6 0}$ \\
$\mathrm{U}$ & 15,6 & $2,76 \mathrm{c}$ & $0,45 \mathrm{~b}$ & $2,27 \mathrm{a}$ \\
$\mathrm{U}(\%)$ & 11,5 & $3,97 \mathrm{a}$ & $0,90 \mathrm{a}$ & $2,14 \mathrm{a}$ \\
& 8,1 & $3,56 \mathrm{ab}$ & $0,97 \mathrm{a}$ & $2,36 \mathrm{a}$ \\
& 4,3 & $3,03 \mathrm{bc}$ & $0,81 \mathrm{ab}$ & $2,43 \mathrm{a}$ \\
\hline \multirow{3}{*}{$\mathrm{T}\left({ }^{\circ} \mathrm{C}\right)$} & 10 & $3,44 \mathrm{ab}$ & $0,86 \mathrm{~b}$ & $3,52 \mathrm{a}$ \\
& 20 & $3,62 \mathrm{a}$ & $1,32 \mathrm{a}$ & $0,92 \mathrm{c}$ \\
& -196 & $2,92 \mathrm{~b}$ & $0,17 \mathrm{c}$ & $2,46 \mathrm{~b}$ \\
\hline \multirow{6}{*}{$\mathrm{U}$} & $15,6 / 10$ & $2,37 \mathrm{a}$ & $0,69 \mathrm{a}$ & $3,86 \mathrm{a}$ \\
& $11,5 / 10$ & $4,79 \mathrm{a}$ & $0,82 \mathrm{a}$ & $2,64 \mathrm{a}$ \\
& $8,1 / 10$ & $3,56 \mathrm{~b}$ & $0,81 \mathrm{a}$ & $3,56 \mathrm{a}$ \\
& $4,3 / 10$ & $3,06 \mathrm{bc}$ & $1,09 \mathrm{a}$ & $4,01 \mathrm{a}$ \\
\cline { 2 - 5 } & $15,6 / 20$ & $2,77 \mathrm{~b}$ & $0,33 \mathrm{~b}$ & $0,69 \mathrm{a}$ \\
& $11,5 / 20$ & $3,91 \mathrm{ab}$ & $1,75 \mathrm{a}$ & $1,00 \mathrm{a}$ \\
& $8,1 / 20$ & $4,05 \mathrm{a}$ & $1,90 \mathrm{a}$ & $1,21 \mathrm{a}$ \\
& $4,3 / 20$ & $3,67 \mathrm{ab}$ & $1,29 \mathrm{a}$ & $0,77 \mathrm{a}$ \\
\cline { 2 - 5 } & $15,6 /-196$ & $3,14 \mathrm{a}$ & $0,33 \mathrm{a}$ & $2,25 \mathrm{a}$ \\
& $11,5 /-196$ & $3,19 \mathrm{~b}$ & $0,12 \mathrm{a}$ & $2,79 \mathrm{a}$ \\
& $8,1 /-196$ & $3,07 \mathrm{a}$ & $0,19 \mathrm{a}$ & $2,30 \mathrm{a}$ \\
& $4,3 /-196$ & $2,27 \mathrm{a}$ & $0,07 \mathrm{a}$ & $2,51 \mathrm{a}$ \\
\hline
\end{tabular}

Médias seguidas de mesma letra na coluna, dentro dos fatores de variação e interação dos fatores não diferem entre si pelo teste de Tukey $(p>0,05)$. CV - coeficiente de variação

Adicionalmente e se considerando o armazenamento na temperatura de $20^{\circ} \mathrm{C}$, o potencial fisiológico foi aceitável por até 240 dias, com exceção das sementes com 15,56\% de água. Oliveira et al. (2006) observaram, em sementes de ipê-amarelo- 
do-cerrado (Tabebuia aurea (Silva Manso) Benth. \& Hook. f. ex. S. Moore) armazenadas em embalagens de papel e em condições ambientais $\left( \pm 24^{\circ} \mathrm{C}\right)$, que a viabilidade ultrapassou os 90 dias. Borba Filho \& Perez (2009) concluíram que sementes de Tabebuia impetiginosa podem ser conservadas embaladas em saco de polietileno, saco de papel Kraft ou lata, quando armazenadas em câmara refrigerada, por 300 dias.

\section{CONCLUSÃO}

A conservação das sementes de ipê-roxo com teores de água de $15,6,11,5,8,1$ e 4,3\%, é favorecida no armazenamento a $10 \mathrm{e}-196^{\circ} \mathrm{C}$.

\section{LITERATURA CITADA}

Bebert, P. A.; Carlesso, V. O.; Silva, R. F.; Araújo, E. F.; Thiébaut, J. T. L.; Oliveira, M. T. R. Qualidade fisiológica de sementes de mamão em função da secagem e do armazenamento. Revista Brasileira de Sementes, v.30, p.40-48, 2008.

Borba Filho, A. B.; Perez, S. C. J. G. A. Armazenamento de sementes de ipê-branco e ipê-roxo em diferentes embalagens e ambientes. Revista Brasileira de Sementes, v.31, p.259269, 2009.

Brasil. Ministério da Agricultura e Reforma Agrária. Secretaria Nacional de Defesa Agropecuária. Brasília: Departamento Nacional de Produção Vegetal. Coordenação de Laboratório Vegetal. Regras para análise de sementes. 1992.395p.

Cabral, E. L.; Barbosa, D. C. A.; Simabukuro, E. A. Armazenamento e germinação de sementes de Tabebuia aurea (manso) Benth. \& Hook. f. ex. S. Moore. Acta Botânica Brasílica, v.17, p.609-617, 2003.

Cromarty, A. S.; Ellis, R. H.; Roberts, E. H. Design of seed storage facilities for genetic conservation. Rome: International Board of Plant Genetic Resources, 1985. 100p.

Degan, P.; Aguiar, I. B.; Sader, R.; Perecin, D.; Pinto, L. R. Influência de métodos de secagem na conservação de sementes de ipê-branco. Revista Brasileira de Engenharia Agrícola e Ambiental, v.5, p.492-496, 2001.

Harrington, J. F. Seed storage and longevity. In: Kozlowski, T. T. (ed.) Seed biology, New York: Academic Press, 1972. p.145245.

Kartha, K. K. Cryopreservation of plant cell and organs. Boca Raton: CRC Press Inc, 1985. 276p.
Kissmann, C.; Scalon, S. P. Q.; Mussury, R.; Robaina, A. D. Germinação e armazenamento de sementes de Albizia hasslerii (Chod.) Burkart. Revista Brasileira de Sementes, v. 31, p. 104-115, 2009.

Lorenzi, H. Árvores Brasileiras: manual de identificação e cultivo de plantas arbóreas nativas do Brasil. Nova Odessa: Plantarum, v.1, 4.ed, 2002.368p.

Marcos Filho, J.; Cícero, S. M.; Silva, W. R. Avaliação da qualidade das sementes. Piracicaba: FEALQ, 1987. 230p.

Marques, M. A.; Rodrigues, T. J. D.; Valeri, S. V.; Malheiros, E. B. Comportamento germinativo de sementes de ipê-amarelo [(Tabebuia chrysotricha (Mart.) Standl.] secadas em câmara seca, armazenadas em diferentes ambientes e submetidas a sete níveis de potencial osmótico. Científica, v.32, p.127$133,2004$.

Martins, L.; Lago, A. A. Conservação de sementes de Cedrela fissilis: Teor de água da semente e temperatura do ambiente. Revista Brasileira de Sementes, v.30, p.161-167, 2008.

Martins, L.; Lago, A. A.; Andrade, A. C. S. Armazenamento de sementes de ipê-branco: Teor de água e temperatura do ambiente. Bragantia, v.68, p.775-780, 2009a.

Martins, L.; Lago, A. A.; Andrade, A. C. S.; Sales, W. R. M. Conservação de sementes de ipê-roxo (Tabebuia impetiginosa (Mart. Ex DC.) Standl.) em nitrogênio líquido. Revista Brasileira de Sementes, v.31, p.071-076, 2009b.

Martins, L.; Lago, A. A.; Sales, W. R. M. Conservação de sementes de ipê-amarelo (Tabebuia chrysotricha (Mart. Ex A. DC.) Standl.) em função do teor de água das sementes e da temperatura do armazenamento. Revista Brasileira de Sementes, v.31, p.086-095, 2009c.

Nascimento, W. M. O.; Cicero, S. M.; Novembre, A. D. L. C. Conservação de sementes de açaí (Euterpe oleraceae Mart.). Revista Brasileira de Sementes, v.32, p.024-033, 2010.

Oliveira, A. K. M.; Scheleder, E. D.; Favero, S. Caracterização morfológica, viabilidade e vigor de sementes de Tabebuia áurea (Silva Manso) Benth. \& Hook. f. ex. S. Moore. Revista Árvore, v.30, p.25-32, 2006.

Oliveira, A. K. M.; Scheleder, E. D.; Favero, S. Caracterização morfológica, viabilidade e vigor de sementes de Tabebuia chrysotricha (Mart. Ex. DC.) Standal. Revista Árvore, v.32, p.1-9, 2008.

Roberts, E. H. Predicting the storage life of seeds. Seed Science and Technology, v.1, p.499-514, 1973.

Vanzolini, S.; Araki, C. A. S.; Silva, A. C. M.; Nakagawa, J. Teste de comprimento de plântula na avaliação da qualidade fisiológica de sementes de soja. Revista Brasileira de Sementes, v.29, p.90-96, 2007. 